\title{
The social determinants of health facility delivery in Ghana
}

\author{
Emmanuel Dankwah ${ }^{1}$, Wu Zeng ${ }^{3}$, Cindy Feng ${ }^{1}$, Shelley Kirychuk ${ }^{2}$ and Marwa Farag ${ }^{1,4^{*}}$ (D)
}

\begin{abstract}
Background: Many women still deliver outside a health facility in Ghana, often under unhygienic conditions and without skilled birth attendants. This study aims to examine the social determinants influencing the use of health facility delivery among reproductive-aged women in Ghana.

Methods: Nationally representative data from the 2014 Ghana Demographic and Health Survey was used to fit univariable and multivariable logistic regression models to estimate the influence of the social determinants on health facility delivery. Andresen's health care utilization model was used as the conceptual framework guiding this study.

Results: Only $72 \%$ of deliveries take place at a health facility in Ghana. The results of the adjusted model indicate that place of residence, financial status, education, religion, parity and perceived need were significantly associated with health facility delivery. First, urban women had a higher likelihood of health facility delivery than rural women (Adjusted Odds ratio $[\mathrm{AOR}]=2.21 ; 95 \%$ Confidence interval $[\mathrm{Cl}]=1.53-3.19$ ). Second, middle-class and rich women were $1.57(95 \% \mathrm{Cl}=1.18-2.08)$ times and $6.91(95 \% \mathrm{Cl}=4.12-11.59)$ times, respectively more likely to deliver at health facility compared to the poor. Third, women with either at least secondary education (AOR $=2.04 ; 95 \% \mathrm{Cl}=1.57-$ 2.64) or primary education ( $A O R=1.39,95 \% \mathrm{Cl}=1.02-1.92)$ were more likely to deliver at health facility than women with no education. In terms of parity, first time mothers were $1.58(95 \% \mathrm{Cl}=1.18-2.12)$ times more likely to deliver at health facility than those who had given birth three or more times before. Finally, regarding perceived need, women who were aware of pregnancy complications were $1.32(95 \% \mathrm{Cl}=1.02-1.70)$ times more likely to use health facility delivery than those who were not informed about pregnancy complications.

Conclusions: First, in spite of Ghana's free maternal health services policy, poorer women were much less likely to have a health facility delivery, which points to the need to understand the indirect costs and other financial barriers preventing women from delivering at a health facility. Second, many of the identified variables influence the demand and not just the supply for health care services, and highlight the importance of the social determinants of health and investments in interventions that extend beyond improving physical access.
\end{abstract}

Keywords: Health facility, Delivery, Reproductive aged women "Social determinants, Birth

\section{Plain English summary}

Delivery outside a health facility in a developing country context often occurs under unhygienic conditions and in the absence of professionally trained skilled birth attendants. Hence, delivery outside a health facility is linked to increased risk of delivery complications including

\footnotetext{
* Correspondence: marwa.farag@usask.ca

'School of Public Health, University of Saskatchewan, 104 Clinic Place, Saskatoon, SK S7N 2Z4, Canada

${ }^{4}$ School of Public Administration and Development Economics, Doha Institute for Graduate Studies, Al Tarfa street, Zone 70, Doha, Qatar Full list of author information is available at the end of the article
}

obstructed labour, retained placenta, postpartum haemorrhage among others. Further, deliveries at outside health facility have contributed to maternal and neonatal mortality. Regrettably, considerable proportions of Ghanaian women still deliver outside a health facility even though health facility delivery has been shown to reduce complications associated with childbirth. This research examined factors potentially influencing women's use of health facility delivery to generate evidence that could help direct public policy towards more effective interventions. In spite of Ghana's free maternal health services policy, the

(c) The Author(s). 2019 Open Access This article is distributed under the terms of the Creative Commons Attribution 4.0 International License (http://creativecommons.org/licenses/by/4.0/), which permits unrestricted use, distribution, and 
findings indicate that about $72 \%$ of Ghanaian women in the childbearing age delivered at health facility. The results of the study revealed that, as expected, women who are poorer, with lower education, who reside in rural areas, who have previously given birth, and were not informed about pregnancy complications, had increased risk of delivering outside a health facility. These findings indicate that factors other than physical access matter a lot in influencing a woman's decision to deliver at a health facility and hence targeted interventions that focus on women who are at higher risk of delivering outside a health facility are needed.

\section{Introduction}

Every year, there are a over 200 million conceptions [1]. However, about $40 \%$ of these conceptions result in pregnancy-related problems among women around the world [1]. Childbirths in health facilities have been recognized as one of the best strategies to avoid maternal mortalities and morbidities and to improve the health of newborns [2-4]. Despite this recognition, a significant percentage of childbirths occur outside health facilities in low-income countries $[3,5]$. One of the tragic consequences of this underutilization is the 830 maternal deaths that occur each day because of pregnancy and labour-related complications [6]. If this consequence is not tragic enough, delivery outside facility also has ramifications for infants. Delivery outside of health facilities contributed to annual neonatal mortalities of 3 million [7] and 2.65 million stillbirths globally in 2008 [8]. Further, home delivery is linked with increased risk of third stage delivery issues including retained placenta, postpartum haemorrhage [9].

Ghana has a population of about 28 million and a population density of 124 . Females account for about 51 $\%$ of the population with an estimated total fertility rate of 4 [6]. According to the Ghana Demographic and Health Survey report [10], inhabitants reside almost equally in urban and rural areas. In Ghana, health facilities administer health care through maternity homes, Community-based Health Planning and Services (CHPS) health post, public, private and mission hospitals. The distribution of health care facilities is skewed in favour of the urban areas.

Maternal deaths continues to be unjustifiably high, though the number of deaths has almost been halved from 634 per 100,000 live births in 1990 to 319 per 100,000 live births in 2015 [6]. This reduction is thought to be the result of the introduction of free maternal care policy, antenatal care (ANC) services and increased institutional deliveries [11-13]. However, even though most pregnant Ghanaian women seem to use ANC services, a large percentage of deliveries still take place outside health facility. This trend is supported by data collected in the 2008
Ghana Demographic and Health Survey (GDHS): 95\% of pregnant women reported utilizing ANC services from skilled personnel, including medical doctors, midwives, and nurses. Nonetheless, only 59\% delivered at health facility in the presence of health professional in 2008 [14]. The Government of Ghana has introduced initiatives such as free maternal health care services, Community-based Health Planning and Services (CHPS), and improved antenatal care and education in an effort to improve access to health facility delivery; these initiatives have been successful in increasing the use of health facility deliver but it remains inequitably distributed $[15,16]$., According to a 2011 survey, 37\% of childbirths occurred at health facility in Northern Ghana, and $52.7 \%$ of deliveries occurred at health facility in rural Ghana [17]. Both of these percentages were well below the national health facility delivery rate of $67.4 \%$ in 2011 [17]. Thus, more efforts are needed to ensure equitable access to this potentially life-saving surgery.

Understanding the determinants of health facility delivery is important for targeting policies and interventions. A body of literature has found that socioeconomic and demographic dynamics affect women's choice of birthplace [18-27], however, inconsistency about how these factors influence women's decisions remains a major concern. In Ghana, some studies have investigated the effect of socio-demographic characteristics on health facility delivery $[18,23,28,29]$. Notwithstanding, these studies were not exhaustive, and highlight the need for further research. For example, none of the studies considered the effect of 'need' on the use of health facility as a place for delivery. Also, previous studies did not use nationwide data making it inaccurate to generalize findings to the entire population. The present study aims to examine social determinants influencing the use of health facility delivery among Ghanaian women of reproductive age.

\section{Methods \\ Study data}

The 2014 Ghana Demographic and Health Survey (GDHS) dataset was used in this study after permission from the MEASURE DHS. GDHS was carried out by the Ghana Statistical Service (GSS), ICF international and Ghana Health Service. The survey used two-stage systematic sampling to select participants from households nested in clusters (enumeration areas) across the all the 10 regions of Ghana. The survey interviewed 9396 women aged 15-49 years with a response rate of 97\% [10]. The GDHS collected information on socio-demographic characteristics and reproductive health issues. Detailed information on the sampling techniques and the questionnaires have been reported elsewhere [10]. 
Conceptual framework for health facility delivery

This research adopted and modified the Andersen's healthcare utilization model to study obstetric services use (place of delivery). Andersen's model considers three types of factors as drivers of health services' use: predisposing, enabling and need factors [30-32].. First, predisposing factors refer to characteristics that exert influence prior to the occurrence of the given health behaviour, by encouraging or inhibiting the uptake of health facility delivery in this case. Predisposing characteristics include all characteristics that might condition individual's perceptions of need and use of health facility delivery. These predisposing factors can take the form of demographic factors (age), reproductive history (parity), cultural beliefs (religion), civil status (marital status), and social structure/factors (education) among other factors $[31,32]$. Second, enabling factors are related to the resources that facilitate or impede the utilization of health services which include financial status, resources in the community and other factors [31, 32]. Third, Andersen's model proposes that "Need" for care is important for influencing behavior [31]. Andersen's model, in addition to an extensive review of empirical literature $[18,23,25$, 26 , was used as guide to select potential factors associated with health facility delivery. The explanatory predictors considered in the study were grouped into predisposing factors (age, marital status, religion, parity, maternal education), enabling factors (financial status and place of residence) and perceived need as shown in Fig. 1. Since this dataset does not include a variable representing actual medical need for health facility delivery, the variable 'told about pregnancy complications' was used as a proxy for perceived need for health facility delivery; the choice of this variable as a proxy for need is based on another study that used a similar variable [33].

\section{Study variables}

The study sample included 4293 women of reproductiveage (15 to 49 years) who responded to the question asking about place of delivery. Birth outside health facility, hereinafter was referred to as home delivery. The outcome variables were coded as follows: health facility delivery = ' 1 ' and, home delivery $=$ ' 0 '. Eight explanatory variables were used: (1) maternal age, (2) financial status, (3) education, (4) place of residence, (5) religion, (6) marital status, and (7) parity, and (8) having been told about pregnancy complications.

Maternal age violated the linearity assumption with a significant quadratic term $(p$-value $=0.001)$ and hence was categorized. As shown in Table 1, explanatory variables were grouped as follows: (1) Maternal age (15-24 years, 25-34 years, 35-49 years); (2) The Financial status variable was created from the Wealth index variable that was available in GDHS dataset. The GDHS generated the Wealth index based on information on household assets using principal component analysis (PCA). The Wealth index variable was comprised of 5 categories namely poorest, poorer, middle, richer and richest. The Financial status variable used in this study is comprised of 3 categories: poor (poorer, poorest), middle, and rich (richer, richest) as reported in a similar studies. [25, 34]; (3) Education was classified into no education, primary (grade 1-6), at least secondary (above grade 6); (4) place of residence (urban, rural); (5) religion (Christian, Islam, Traditional and Others); (6) marital status (married, unmarried); (7) parity (1 birth, 2 births, 3 births or more); (8) told about pregnancy complications (yes, no).

\section{Statistical analyses}

The present study used sampling weights provided by GDHS. The weighting factor from the survey was used

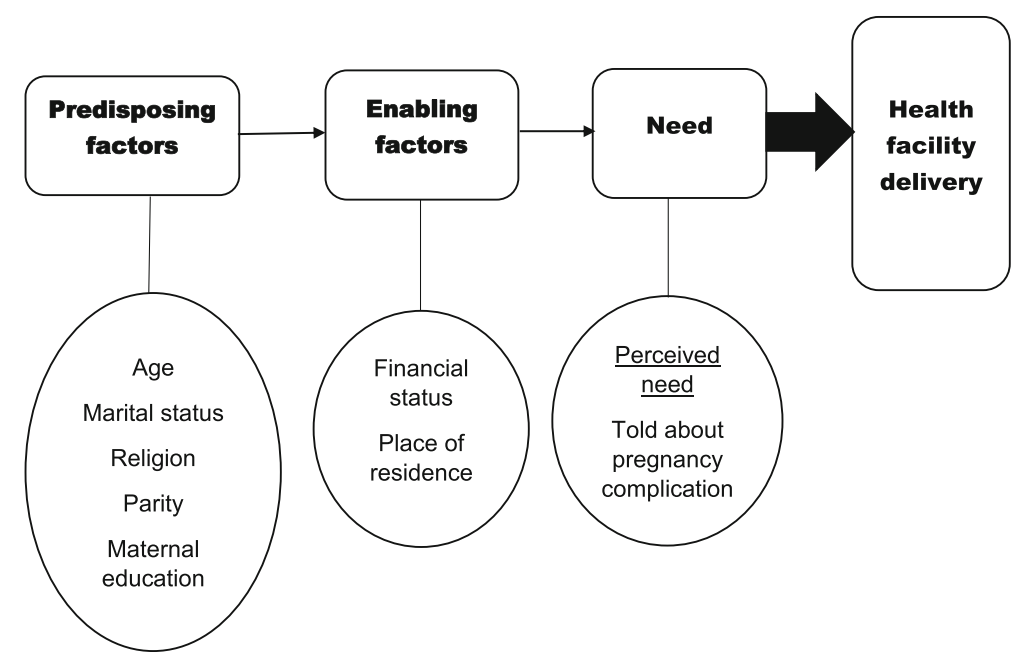

Fig. 1 Theoretical framework adapted from Andersen's Health utilization model 
Table 1 Study variable description

\begin{tabular}{|c|c|c|}
\hline Variable name & Description & $\begin{array}{l}\text { Level of } \\
\text { measurement }\end{array}$ \\
\hline \multirow{2}{*}{$\begin{array}{l}\text { Place of } \\
\text { delivery }\end{array}$} & \multirow[t]{2}{*}{ Respondents place of delivery } & $0=$ Home delivery \\
\hline & & $1=$ Health facility \\
\hline \multirow[t]{3}{*}{ Age } & \multirow[t]{3}{*}{ Maternal age (years) } & $1=15$ to 24 \\
\hline & & $2=25$ to 34 \\
\hline & & $3=35$ to 49 \\
\hline \multirow[t]{3}{*}{ Financial status } & \multirow{3}{*}{$\begin{array}{l}\text { Financial status of the } \\
\text { household }\end{array}$} & $1=$ Poor \\
\hline & & $2=$ Middle \\
\hline & & $3=$ Rich \\
\hline \multirow[t]{2}{*}{ Marital status } & \multirow[t]{2}{*}{ Current marital status } & $0=$ Unmarried \\
\hline & & $1=$ Married \\
\hline \multirow[t]{2}{*}{ Residence } & \multirow[t]{2}{*}{ Place of residence } & $1=$ Urban \\
\hline & & $2=$ Rural \\
\hline \multirow[t]{3}{*}{ Education } & \multirow[t]{3}{*}{ Highest educational level } & $1=$ No Education \\
\hline & & $2=$ Primary \\
\hline & & $\begin{array}{l}3=\text { at least } \\
\text { Secondary }\end{array}$ \\
\hline \multirow[t]{3}{*}{ Religion } & \multirow{3}{*}{$\begin{array}{l}\text { Religious affiliation of the } \\
\text { women }\end{array}$} & $1=$ Christians \\
\hline & & $2=$ Islam \\
\hline & & $3=$ Traditional/other \\
\hline \multirow[t]{3}{*}{ Parity } & \multirow[t]{3}{*}{ Number of Births } & $1=1$ birth \\
\hline & & $2=2$ births \\
\hline & & $3=3$ or more births \\
\hline \multirow{2}{*}{$\begin{array}{l}\text { Pregnancy } \\
\text { complications }\end{array}$} & \multirow{2}{*}{$\begin{array}{l}\text { Told about pregnancy } \\
\text { complications }\end{array}$} & $\mathrm{No}=0$ \\
\hline & & Yes $=1$ \\
\hline
\end{tabular}

to address sampling error and non-response to ensure validity of the findings. All analyses were conducted in SAS version 9.4 (SAS Institute, Cary, NC, USA). Proportions and frequencies were tabulated for each of the categorical independent variables. The effect of the risk factors on health facility delivery were fitted using a logit model stated as:

$$
\begin{aligned}
& p(Y i=1)=p i \\
& \operatorname{logit}(\mathrm{pi})=\beta_{0}+\beta_{1} \mathrm{X}_{1}+\beta_{2} \mathrm{X}_{2} \ldots+\beta_{\mathrm{k}} \mathrm{X}_{\mathrm{ki}}
\end{aligned}
$$

where pi is the probability of health facility delivery among the $i$ th women; $\beta_{0}$ is the intercept; $\beta_{\mathrm{k}}$ is the regression parameters; $\mathrm{Xi}$ is the independent variables; $\mathrm{Yi}$ is the outcome of interest.

This study employed Taylor series linearization method, which is a variance estimation procedure used by PROC SURVEYLOGISTIC in SAS, to adjust for clustering effect. Univariable logistic regression models were used to screen independent variables for further analysis. In the unadjusted model, risk factors with a liberal of $p$ value $\leq 0.25$ were selected for inclusion in the multivariable logistic regression model based on the Hosmer and Lemeshow publication [35]. This lenient pvalue cut-off was used to prevent missing important factors whose effect could be suppressed or concealed by confounding effect. Multicollinearity among select independent variables for the adjusted model was checked, variance inflation factor (VIF) greater than 2.5 was considered collinear. A multivariate logistic regression model was fitted to examine the link between health facility delivery and explanatory factors. The manual backward elimination technique was employed for model building in this research [36]. First, all factors that were selected for the adjusted model were included. Factors with the highest $p$-values and widest 95\% confidence intervals were selected for elimination from the model one at a time until all the predictors in the model were significant at $p$-value $\leq 0.05$.

The odds ratios and corresponding 95\% confidence intervals were computed for all the significant variables in the adjusted model.. Two-way interactions among significant factors in the adjusted model were tested. The model with the smallest Akaike's Information Criterion (AIC) was selected as a parsimonious model.. Further, area under the Receiver Operating Characteristic (ROC) was used for model diagnostics to assess the discriminatory power of the model on the study outcome.

\section{Results \\ Descriptive results}

Four thousand two hundred ninety three women between the ages of 15 and 49 responded to the place of delivery question in the GDHS 2014 (Table 2). The study population was reasonably young with an average age of 29.7 years $(S D=9.71)$. About $72 \%$ of women reported health facility delivery, while $28 \%$ used home delivery.

Age

Almost half (47.6\%) of the women fell between the ages of 25-34 years. About one-third (31\%) of the women's ages ranged between 35 and 49 years, while roughly 1 in 5 (21\%) were between 15 and 24 years. Across these age groups, similar trends were observed. About threequarters $(73.9 \%)$ of the women aged $15-24$ years delivered at health facility. Likewise, $73 \%$ and $70.3 \%$ reported having health facility delivery among 25-34 and 35-49-year-olds, respectively (Table 2 ).

\section{Residence}

More than half $(53.8 \%)$ of the women lived in rural areas. Among these rural dwellers, about two-thirds $(60 \%)$ used health facility for delivery whereas 
Table 2 Distribution of health facility delivery by social determinants $(N=4293)$

\begin{tabular}{|c|c|c|c|}
\hline Predictors & N (\%) & $\begin{array}{l}\text { Health facility } \\
\text { delivery } \\
N=3107(\%)\end{array}$ & $\begin{array}{l}P \text {-value } \\
\text { (Chi-Sq) }\end{array}$ \\
\hline
\end{tabular}

Age

$\begin{array}{lll}15-24 & 922(21.4) & 681(73.9) \\ 25-34 & 2026(47.6) & 1480(73.0) \\ 35-49 & 1345(31.0) & 946(70.3)\end{array}$

Place of Residence

$\begin{array}{llll}\text { Urban } & 1777(46.2) & 1595(89.8) & <0.0001^{*} \\ \text { Rural } & 2516(53.8) & 1512(60.0) & \end{array}$

Education

$\begin{array}{lll}\text { No Education } & 1419(26.1) & 766(54.0) \quad<0.0001^{*} \\ \text { Primary } & 869(19.6) & 602(69.3) \\ \text { Secondary and above } & 2005(54.3) & 1739(86.7)\end{array}$

Financial status

$\begin{array}{llll}\text { Poor } & 2241(41.3) & 1287(57.4) & <0.0001^{*} \\ \text { Middle } & 812(20.0) & 634(78.0) & \\ \text { Rich } & 1240(38.7) & 1186(95.6)\end{array}$

Marital Status

\begin{tabular}{lccc} 
Married & $2801(61.7)$ & $2035(72.7)$ & 0.6 \\
Unmarried & $1492(38.3)$ & $1072(71.8)$ & \\
$\begin{array}{l}\text { Religion } \\
\text { Christian }\end{array}$ & $3047(71.0)$ & $2321(76.2)$ & $<0.0001^{*}$ \\
Muslim & $922(21.4)$ & $671(72.8)$ & \\
$\begin{array}{l}\text { Traditional/other } \\
\text { Parity of the women }\end{array}$ & $324(7.6)$ & $115(35.5)$ & \\
1 birth & $934(22.8)$ & $790(84.6)$ & $<0.0001^{*}$ \\
2 births & $839(20.3)$ & $657(78.3)$ & \\
3 or more births & $2520(56.9)$ & $1660(65.9)$ & \\
Told about pregnancy complications & & \\
Yes & $3423(82.5)$ & $2579(75.3)$ & $<0.0001^{*}$ \\
No & $724(17.5)$ & $496(68.5)$ & \\
\hline
\end{tabular}

$N$ number of observations; $\%$, percent; $\pm N=4147$, due to missing observations; *significant at $p$-value of $0.005 ; 2014$ GDHS data

approximately 9 in 10 (89.8\%) urban dwellers delivered at health facility (Table 2).

\section{Education}

Over a half (54.3\%) of the women had attained at least secondary education. About a quarter (26.1\%) of the women had no formal education, and nearly one-fifth (19.6\%) had attained primary education. Regarding health facility delivery, more than half (54\%) of the women with no education reported having had delivery at a health facility. For women with primary and at least secondary education, health facility delivery was 69.3 and $86.7 \%$ respectively (Table 2 ).

\section{Financial status}

The "poor" category included about $41.3 \%$ of the population while the "middle" income group included about $20 \%$, and more than one-third $(38.7 \%)$ of the women were in the "rich" group. Regarding delivery place, roughly three-fifths (57.4\%) of the poor women reported having had health facility delivery. Among middle-class and rich women, 78 and $95.6 \%$ births respectively occurred at health facility (Table 2).

\section{Marital status}

The majority $(61.7 \%)$ of the women were married. Out of married women, health facility deliveries accounted for $72.7 \%$. Similarly, $71.8 \%$ of unmarried women reported having health facility delivery (Table 2).

\section{Religion}

Most of the women (71.0\%) were Christians. The second largest religious group was Muslim (21.4\%), followed by traditional and other beliefs (7.6\%). Health facility delivery trends were alike among Christian and Muslim women, but there was a marked difference among women with traditional and other beliefs. The study found that about three-quarters of Christians (76.2\%) and Muslims (72.8\%) reported having had health facility delivery. Also, a much smaller percentage $(35.5 \%)$ of women with traditional and other beliefs had delivery at health facility (Table 2).

\section{Parity}

More than half $(56.9 \%)$ of the women had given birth at least 3 times whilst $22.8 \%$ of the women had given birth once, and $20.3 \%$ had given birth twice. Among first time mothers, $84.6 \%$ delivered at health facility. Also, $78.3 \%$ of women who had given birth twice used health facility for delivery. Lastly, among mothers with three or more children, $65.9 \%$ of deliveries took place at health facility (Table 2).

\section{Perceived need}

Women who were informed about pregnancy complications had health facility delivery higher than their counterparts who were not aware of pregnancy complication (75.3\% vs. $68.5 \%)$.

\section{Univariable analysis results}

The associations between select social determinants and health facility delivery were tested (Table 3). Unadjusted analyses revealed the following associations:

\section{Age}

The study found a weak association between the age of a woman and health facility delivery. The univariable analysis produced point estimates a little over one for women aged 25-34 years (Unadjusted OR $=1.09 ; 95 \% \mathrm{CI}=0.91-$ 
1.30) and those aged 35-49 years (Unadjusted $\mathrm{OR}=1.03$; $95 \% \mathrm{CI}=0.81-1.31)$ relative to women aged $15-24$ years. Additionally, the overall $p$-value (0.6) was greater than 0.25 , and hence was not selected for the multivariable logistic regression model (Table 3).

\section{Residence}

Women living in urban areas were $6.71(95 \% \mathrm{CI}=4.76-$ 9.44) times more likely to deliver at health facility than rural residents (Table 3 ).

\section{Education}

Compared to women with no education, secondary or higher educated women $5.92(95 \% \mathrm{CI}=4.43-7.90)$ times more likely to deliver at health facility. Women with primary education were $1.89(95 \% \mathrm{CI}=1.40-2.55)$ times more likely to report having health facility delivery than women with no education (Table 3).

\section{Financial status}

The odds of having health facility delivery among rich women were about $18.55(95 \% \mathrm{CI}=12.54-27.44)$ times when compared to the poor. Moreover, middle class

Table 3 Unadjusted Odds ratio and 95\% confidence interval of having health facility delivery by socio-demographic risk factors in the univariable logistic regression analyses

\begin{tabular}{|c|c|c|}
\hline Predictors & $\begin{array}{l}\text { Unadjusted Odds Ratio } \\
\text { (95\% Confidence Interval) }\end{array}$ & $P$-value \\
\hline \multicolumn{3}{|l|}{ Age (Ref: 15-24) } \\
\hline $25-34$ & $1.09(0.91,1.30)$ & \multirow[t]{2}{*}{0.6} \\
\hline $35-49$ & $1.03(0.81,1.31)$ & \\
\hline \multicolumn{3}{|l|}{ Residence (Ref: Rural) } \\
\hline Urban & $6.71(4.76,9.44)$ & $<0.0001$ \\
\hline \multicolumn{3}{|c|}{ Highest Education Level (Ref: No education) } \\
\hline Primary & $1.89(1.40,2.55)$ & \multirow[t]{2}{*}{$<0.0001$} \\
\hline Secondary and above & $5.92(4.43,7.90)$ & \\
\hline \multicolumn{3}{|l|}{ Financial status (Ref: Poor) } \\
\hline Middle & $2.69(2.03,3.59)$ & \multirow[t]{2}{*}{$<0.0001$} \\
\hline Rich & $18.55(12.54,27.44)$ & \\
\hline \multicolumn{3}{|c|}{ Religion (Ref: Traditional/other) } \\
\hline Muslim & $4.20(2.43,7.26)$ & \multirow[t]{2}{*}{$<0.0001$} \\
\hline Christian & $5.85(3.79,9.0)$ & \\
\hline \multicolumn{3}{|c|}{ Marital status (Ref: Unmarried) } \\
\hline Married & $1.05(0.85,1.28)$ & 0.7 \\
\hline \multicolumn{3}{|c|}{ Parity of the women (Ref: 3 or more births) } \\
\hline 1 birth & $2.77(2.19,3.50)$ & \multirow[t]{2}{*}{$<0.0001$} \\
\hline 2 births & $1.73(1.35,2.21)$ & \\
\hline \multicolumn{3}{|c|}{ Told about pregnancy complications (Ref: No) } \\
\hline Yes & $1.65(1.29,2.11)$ & $<0.0001$ \\
\hline
\end{tabular}

women were $2.69(95 \% \mathrm{CI}=2.03-3.59)$ times more likely to deliver at health facility than poor women (Table 3 ).

\section{Religion}

Muslims and Christians were $4.20(95 \% \mathrm{CI}=2.43-7.26)$ times and $5.85(95 \% \mathrm{CI}=3.79-9.0)$ times respectively, more likely to deliver at health facility (Table 3 ).

\section{Marital status}

The relationship between marital status and health facility delivery in this study was not significant (unadjusted $\mathrm{OR}=1.05 ; \quad 95 \% \mathrm{CI}=0.85-1.28)$. Further, $p$-value $(0.7)$ higher than 0.25 was identified. In view of that, marital status was not considered for further analysis in the adjusted model (Table 3).

\section{Parity}

The higher the number of times a woman give birth, the less likely to resort to health facility delivery in subsequent births. The results revealed that women who had given birth twice were $1.73(95 \% \mathrm{CI}=1.35-2.21)$ times more likely to deliver at health facility than mothers with three or more births. First-time mothers were 2.77 $(95 \% \mathrm{CI}=2.19-3.50)$ times more likely to have health facility delivery than women who had given birth three or more times.

\section{Perceived need}

Women who were aware of pregnancy complications had a higher likelihood of using health facility for delivery relative to women who were not informed about pregnancy complications (unadjusted $\mathrm{OR}=1.65$; $95 \% \mathrm{CI}=1.29-2.11)$.

\section{Multivariable analysis results}

Only the maternal age and marital status variables were not considered in the adjusted model. In this study, the significant factors associated with health facility delivery in the multivariable logistic regression analysis are presented in Table 4.

\section{Residence}

Women living in urban areas were $2.21(95 \% \mathrm{CI}=1.53-$ 3.19) times more likely to use health facility for delivery than their rural counterparts.

\section{Education}

Women who attained at least secondary education were $2.04(95 \% \mathrm{CI}=1.57-2.64)$ times more likely to deliver at health facility than uneducated women. Likewise, women who had a primary education were $1.39(95 \% \mathrm{CI}=1.02-$ 1.92) times more likely to have health facility delivery relative to those without education. 


\section{Financial status}

The odds of having health facility delivery were 6.91 $(95 \% \mathrm{CI}=4.12-11.59)$ times higher among the rich than poor women. Compared to poor women, middle-level women were $1.57(95 \% \mathrm{CI}=1.18-2.08)$ times more likely to deliver at health facility.

\section{Religion}

The likelihood of health facility delivery among Christians was $2.53(95 \% \mathrm{CI}=1.67-3.84)$ times higher than traditional and other believers. Likewise, Muslims were $2.75(95 \% \mathrm{CI}=1.61-4.69)$ times more likely to deliver at health facility than traditional and other believers.

\section{Parity}

Odds of having health facility delivery among women who had given birth once were $1.58(95 \% \mathrm{CI}=1.18-2.12)$ times higher than mothers with 3 or more births. Conversely, no significant difference was detected between women who had given birth twice and those with three or more childbirth experience (Adjusted Odds ratio = 1.07; $95 \% \mathrm{CI}=0.82-1.39)$ ).

\section{Perceived need}

The analysis revealed that women who were aware of pregnancy complications were 1.32 (95\%CI: 1.02-1.70) times more likely to deliver at health facility when compared with women who were not informed about pregnancy-related issues.

Table 4 Adjusted Odds ratio and 95\% Confidence interval of having health facility delivery by socio-demographic risk factors in the multivariable logistic regression analyses

\begin{tabular}{|c|c|c|}
\hline Predictors & $\begin{array}{l}\text { Adjusted Odds Ratio } \\
\text { (95\% Confidence Interval) }\end{array}$ & $P$-value \\
\hline \multicolumn{3}{|l|}{ Residence (Ref: Rural) } \\
\hline Urban & $2.21(1.53,3.19)$ & $<0.0001^{*}$ \\
\hline \multicolumn{3}{|c|}{ Highest Education Level (Ref: No education) } \\
\hline Primary & $1.39(1.02,1.92)$ & $0.04^{*}$ \\
\hline Secondary and above & $2.04(1.57,2.64)$ & $<0.0001^{*}$ \\
\hline \multicolumn{3}{|l|}{ Financial status (Ref: Poor) } \\
\hline Middle & $1.57(1.18,2.08)$ & $0.002^{*}$ \\
\hline Rich & $6.91(4.12,11.59)$ & $<0.0001^{*}$ \\
\hline \multicolumn{3}{|c|}{ Religion (Ref: Traditional/Other religion) } \\
\hline Muslim & $2.75(1.61,4.69)$ & $<0.0001^{*}$ \\
\hline Christian & $2.53(1.67,3.84)$ & $<0.0001^{*}$ \\
\hline \multicolumn{3}{|c|}{ Parity of the women (Ref: 3 or more births) } \\
\hline 1 birth & $1.58(1.18,2.12)$ & $0.002 *$ \\
\hline 2 births & $1.07(0.82,1.39)$ & 0.6 \\
\hline \multicolumn{3}{|c|}{ Told about pregnancy complications (Ref: No) } \\
\hline Yes & $1.32(1.02,1.70)$ & $0.03^{*}$ \\
\hline
\end{tabular}

\section{Discussion}

Home delivery especially without skilled supervision is a major concern not only in Ghana but also in other developing countries including Kenya [27] and India [26]. Even after the introduction of CHPS and the implementation of a health policy that granted free access to maternal health care, a significant proportion of Ghanaian women still deliver at home. Our study revealed that about $72 \%$ of childbirths in Ghana occur at health facility. Though, this percentage is an improvement from the $61.9 \%$ health facility delivery rate reported by Boah et al. [28], yet it is unacceptably low if the goal is to achieve universal coverage in terms of health facility delivery.

In Ghana, there are a number of factors that ultimately influence women's decision about the place of their birth. These factors are dynamic, and reflect the complex nature of childbirth, women's autonomy, and familial relationships. In our study, women's age and marital status were not significantly associated with health facility delivery. These results are supported by some of the literature [19, 25]. However, other literature suggests that these factors may have predictive value [22, 24, 25, 34]. Recognizing that there is a discrepancy is important. Such a discrepancy suggests that more needs to be done to effectively contextualize women's decision-making, and the factors that will and will not be predictive given that context.

Based on the results of our study, factors that may be important for women's decision-making about the place of their delivery include place of residence, education, financial status, religion, parity and perceived need. Recognition of a host of factors that have the potential to be predictive of women's decision-making reflects the need to take a public health approach that emphasizes the social determinants of health when examining health facility deliveries. A social determinants approach recognizes that health extends far beyond the medical model. Using a social determinants' lens to improve health facility deliveries has the potential to transform Ghanaian women's birthing experiences, health outcomes, and their children's wellbeing. However, the relevance of each of our study's factors must be assessed in light of the literature.

\section{Residence}

Place of residence tends to influence the choice women make about place of delivery [37]. In our study, only about half of births among women living in rural areas occurred at a health facility, and this is consistent with statistics reported by Ghana Health Service [38]. Women living in urban areas were more likely to deliver at health facility than rural dwellers in the multivariate regression model controlling for other important factors. These findings are consistent with results reported in other African countries, including Ethiopia [39], Nigeria [40], 
and Kenya [24]. The disparity between rural and urban women may be a consequence of the physical location of health facilities. That is, more maternal health facilities are located in urban areas, meaning that those facilities are more accessible to the women that live there. Urban women do not face the same barriers to physical access that rural women do; poor roads and the remoteness of some communities mean that health facility delivery may be not be a viable option for some rural women. Further, the proximity of health facilities in urban areas means there is a more concrete network between various health services, and urban women may be able to receive referrals and make use of multidisciplinary teams to a greater extent than rural women. Given the strong association between place of residence and home delivery, efforts directed at improving rural health services in Ghana may be warranted.

\section{Education}

A woman's choice regarding where she delivers her child and her education level are closely linked [27]. Upon holding everything else constant, as the level of education increased, the likelihood of health facility delivery increased. This finding is consistent with other studies $[19,23,34,41,42]$. This trend is thought to be a function of the improved health literacy among educated women. That is, educated women are better able to understand and become informed about health care issues. As a result, their health care decisions reflect this awareness [43]. This finding indicates that creating public health programming that targets women with lower levels of education may be an effective way to increase the number of health facility deliveries.

\section{Financial status}

In our study, the poorer the woman, the less likely it is that she delivers at health facility. This trend is mirrored in studies conducted in Kenya [27, 43], Ghana [25], and Nigeria [42]. Given that Ghana's maternal health care is free, our results suggest that, aside from the cost of health services, other economic factors influence women's decision-making when it comes to choice of delivery place. This nuanced interpretation draws a crucial distinction between the Ghanaian context and other jurisdictions, and must be explored. This interpretation is affirmed in some literature, where a women's inability to purchase maternal health services was not the sole reason for opting to deliver outside of a health facility [24]. Other contributing factors may include: the cost of transportation, time spent traveling, and miscellaneous fees associated with receiving care in health facilities [44, 45]. This broad interpretation of the costs associated with health facility deliveries is crucial for gaining a deeper understanding of how financial status influences women's decisions to resort to home delivery.

\section{Religion}

Women who were Christians or Muslims were more likely to deliver at health facility than those who had traditional and other beliefs. This result is supported by other research conducted in Ghana [18], but contrary to the results from a research study conducted in Uganda [19]. Given the differences in socio-demographics between Uganda and Ghana, the discrepancy may be a function of the different religious make-ups. The reason why women with traditional and other beliefs are less likely to deliver at health facility may be because of their opposition to modern health services. These women may perceive pregnancy and labour as natural occurrences that should be free of medical intervention, except in the case of an emergency $[5,46]$. Considering that religion is highly personal, public health interventions aimed at connecting these women with maternal health services must be developed with the utmost cultural competence to help discourage home deliveries and its associated consequences.

\section{Parity}

The number of times a woman had given birth was strongly associated with health facility delivery. As birthing times increased, the likelihood of a home delivery decreased. In a similar study conducted in rural south Ghana, first-time mothers were more likely to have health facility delivery than women who had previously given birth more than twice [23]. This direct association is consistent with findings from literature [24, 27, 41]. One possible explanation for this finding could be that if a woman received poor health services during her previous deliveries, she may be less likely to access those services again [24, 47, 48]. Apart from these negative experiences, self-confidence from previous labours [19], lower complications from previous pregnancy, and the notion that home delivery is a sign of bravery [5], tend to aggravate the likelihood of delivering at home. Unpacking this trend is important because if the quality of maternal health services is detracting women from using them, then improvements must be made. Further investigation is needed to examine the association between quality of maternal health care and health facility delivery among multiparous. Given the data source, this was not possible in the current study. However, such an investigation would provide important insights about the quality of maternal health care services, and their ability to adequately meet expectant mothers' needs. Eventually, it would assist in improving health facility deliveries among multiparous women. 


\section{Perceived need}

The study identified that health facility delivery was significantly associated with perceived need of the mothers but the association was not strong. Perceived need i.e. knowledge about pregnancy complications was associated with health facility delivery in this study. The study result is consistent with some earlier studies in the African subregion $[28,33,49]$ that found greater use of health facility delivery among mothers who were informed about pregnancy and delivery issues. This result exposes the quality of health information mothers received during antenatal care (ANC) since the rate of ANC uptake have been reported to be very high in Ghana by other studies [10, 28]. This finding points to the need to give increased attention to health education about potential delivery associated complications as part of ANC in Ghana.

\section{Study strength and limitations}

This study used the most recent nationally representative Demographic and Health survey data to examine the social determinants of health facility delivery use. The results from the present study contributes to the body literature on the social determinants of health and highlights the need for targeted maternal health programming especially in developing economies. However, this research was characterized with some limitations which should be recognised in the interpretation of the findings. A major limitation in this study is that data pertaining to the sociodemographic factors was collected during the survey period, and not at the time of delivery. Also, as result of lack of data on actual medical need, the variable "told about pregnancy complications" was used as a proxy for perceived need and hence conclusions based on this variable should be drawn with caution.

\section{Conclusion}

In conclusion, this study adds to the body of international literature on the social determinants of health as it finds that there is a host of factors that influences Ghanaian women's decision about health facility delivery. Many of these factors are demand side factors and hence improving physical access alone is unlikely to create the important changes needed to increase health facility delivery among Ghanaian women and improve equitable access to it. In addition, in spite of Ghana's free maternal health care policy, poorer women were much less likely to have a health facility delivery, which raises the issue of other indirect financial barriers to access and the importance of tackling these barriers. Taken together, there is a need for effective maternal health programming to target poorer, less educated women who reside in rural areas, and who have previously given birth to increase health facilities deliveries in Ghana and hence improve maternal health outcomes.

\section{Abbreviations}

AIC: Akaike's Information Criterion; ANC: Antenatal Care; AOR: Adjusted Odds Ratio; AUC: Area under the curve; CHPS: Community-based Health Planning and Services; Cl: Confidence Interval; GDHS: Ghana Demographic and Health Survey; GSS: Ghana Statistical Service; OR: Odds Ratio; PCA: Principal Component Analysis; ROC: Receiver operating characteristics; SD: Standard deviation; VIF: Variance Inflation Factor; WHO: World Health Organization

\section{Acknowledgements}

The author acknowledges with gratitude the release of the 2014 GDHS data for the study by MEASURE DHS. We are grateful to the participants of the study and the valuable comments from the readers of this manuscript.

\section{Authors' contributions}

All authors participated in all stages of the preparation of the manuscript and approved its final version for submission. ED conceived of the study, took the lead role in conducting the analyses and writing the manuscript. CF and WZ supervised the data analyses and interpretation of findings. SK participated in the design of the study and contributed to revising the analyses and writing. MF supervised developing the research questions, models, and the interpretations of the associated results as well as contributed to the writing of the paper.

\section{Funding}

The author declares no financial support for this research paper.

\section{Availability of data and materials}

The datasets analyzed during the current study are available in the MEASURE DHS repository, https://www.dhsprogram.com/data/dataset_admin/login_ main.cfm. ${ }^{\text {[GHIR72DT] }}$

\section{Ethics approval and consent to participate}

The study used secondary data from the 2014 GDHS. MEASURE DHS granted the request to use the data for this study. Additionally, ethical approval was sought before the collection of the survey data. Consenting women were included in the survey and were offered the opportunity to withdraw at any stage. Ethical review was not required since the study relied exclusively on secondary data and the findings do not generate identifiable information.

Consent for publication

Not applicable in this study.

\section{Competing interests}

The authors declare that they have no competing interests.

\section{Author details}

${ }^{1}$ School of Public Health, University of Saskatchewan, 104 Clinic Place, Saskatoon, SK S7N 2Z4, Canada. ${ }^{2}$ College of Medicine, Canadian Centre for Health and Safety in Agriculture (CCHSA), University of Saskatchewan, 104 Clinic Place, Saskatoon, SK S7N 2Z4, Canada. ${ }^{3}$ The Heller School for Social Policy and Management, Brandeis University, 415 South St, Waltham, MA 02453, USA. ${ }^{4}$ School of Public Administration and Development Economics, Doha Institute for Graduate Studies, Al Tarfa street, Zone 70, Doha, Qatar.

Received: 13 March 2019 Accepted: 13 June 2019

Published online: 10 July 2019

\section{References}

1. Yanagisawa S, Oum S, Wakai S. Determinants of skilled birth attendance in rural Cambodia. Tropical Med Int Health. 2006;11(2):238-51.

2. Filippi V, Ronsmans C, Campbell OM, Graham WJ, Mills A, Borghi J, Koblinsky M, Osrin D. Maternal health in poor countries: the broader context and a call for action. Lancet. 2006;368(9546):1535-41.

3. Koblinsky M, Matthews Z, Hussein J, Mavalankar D, Mridha MK, Anwar I, Achadi E, Adjei S, Padmanabhan P, van Lerberghe W. Going to scale with professional skilled care. Lancet. 2006;368(9544):1377-86.

4. Adegoke A, Van Den Broek N. Skilled birth attendance-lessons learnt. BJOG Int J Obstet Gynaecol. 2009;116(s1):33-40.

5. Montagu D, Yamey G, Visconti A, Harding A, Yoong J. Where do poor women in developing countries give birth? A multi-country analysis of demographic and health survey data. PLoS One. 2011;6(2):e17155. 
6. WHO: Trends in maternal mortality: 1990-2015: estimates from WHO, UNICEF, UNFPA, World Bank Group and the United Nations Population Division: executive summary. 2015.

7. WHO: Neonatal and perinatal mortality: country, regional and global estimates. 2006.

8. Lawn JE, Blencowe H, Pattinson R, Cousens S, Kumar R, Ibiebele I, Gardosi J, Day LT, Stanton C. Committee LSSSS: Stillbirths: Where? When? Why? How to make the data count? Lancet. 2011;377(9775):1448-63.

9. Tuladhar H, Dali S, Pradhanang V. Complications of home delivery: a retrospective analysis. J Nepal Med Assoc. 2005;(159):44

10. Ghana Statistical Service (GSS), Ghana Health Service (GHS), and ICF International. 2014 Ghana Demographic and Health Survey; 2015. https:// dhsprogram.com/pubs/pdf/fr307/fr307.pdf. Accessed 10 June 2018.

11. Magoma M, Requejo J, Campbell OM, Cousens S, Filippi V. High ANC coverage and low skilled attendance in a rural Tanzanian district: a case for implementing a birth plan intervention. BMC Pregnancy Childbirth. 2010;10(1):13.

12. Bhutta ZA, Lassi ZS, Mansoor N. Systematic review on human resources for health interventions to improve maternal health outcomes: evidence from developing countries: World Health Organization (WHO). Aga Khan University: Division of Women and Child Health; 2010.

13. Abera M, Belachew T. Predictors of safe delivery service utilization in Arsi zone, south-East Ethiopia. Ethiop J Health Sci. 2011;21(3):95-106.

14. Ghana Statistical Service (GSS), Ghana Health Service (GHS), and ICF Macro. Ghana Demographic and Health Survey 2008. Accra, Ghana, 2009.https:// dhsprogram.com/pubs/pdf/fr307/fr307.pdf. Accessed 20 Sept 2018.

15. Penfold S, Harrison E, Bell J, Fitzmaurice A. Evaluation of the delivery fee exemption policy in Ghana: population estimates of changes in delivery service utilization in two regions. Ghana Med J. 2007;41(3):100.

16. Mensah J, Oppong JR, Schmidt CM. Ghana's National Health Insurance Scheme in the context of the health MDGs: an empirical evaluation using propensity score matching. Health Econ. 2010;19(S1):95-106.

17. Ghana statistical service: Ghana multiple indicator cluster survey with an enhanced malaria module and biomarker with enhanced module biomarker. 2011

18. Amoakoh-Coleman M, Ansah EK, Agyepong IA, Grobbee DE, Kayode GA, Klipstein-Grobusch K. Predictors of skilled attendance at delivery among antenatal clinic attendants in Ghana: a cross-sectional study of population data. BMJ Open. 2015:5(5):e007810.

19. Anyait A, Mukanga D, Oundo GB, Nuwaha F. Predictors for health facility delivery in Busia district of Uganda: a cross sectional study. BMC Pregnancy Childbirth. 2012;12(1):132

20. Fotso J-C, Ezeh AC, Essendi H. Maternal health in resource-poor urban settings: how does women's autonomy influence the utilization of obstetric care services? Reprod Health. 2009;6(1):9.

21. Van Eijk AM, Bles HM, Odhiambo F, Ayisi JG, Blokland IE, Rosen DH, Adazu K, Slutsker $\mathrm{L}$, Lindblade KA. Use of antenatal services and delivery care among women in rural western Kenya: a community based survey. Reprod Health. 2006;3(1):2.

22. Ochako R, Fotso J-C, Ikamari L, Khasakhala A: Utilization of maternal health services among young women in Kenya: insights from the Kenya demographic and health survey, 2003 BMC Pregnancy Childbirth 2011, 11(1):1.

23. Manyeh AK, Akpakli DE, Kukula V, Ekey RA, Narh-Bana S, Adjei A, Gyapong M. Socio-demographic determinants of skilled birth attendant at delivery in rural southern Ghana. BMC Res Notes. 2017;10(1):268.

24. Kitui J, Lewis S, Davey G. Factors influencing place of delivery for women in Kenya: an analysis of the Kenya demographic and health survey, 2008/2009. BMC Pregnancy Childbirth. 2013;13(1):40.

25. Ameyaw EK, Tanle A, Kissah-Korsah K, Amo-Adjei J. Women's health decision-making autonomy and skilled birth attendance in Ghana. Int J Reprod Med. 2016;2016:1-9.

26. Bhattacharyya S, Srivastava A, Roy R, Avan Bl. Factors influencing women's preference for health facility deliveries in Jharkhand state, India: a cross sectional analysis. BMC Pregnancy Childbirth. 2016;16(1):50.

27. Gitonga $E$, Muiruri F. Determinants of health facility delivery among women in Tharaka Nithi county, Kenya. Pan Afr Med J. 2016;25(Suppl 2):9-9.

28. Boah M, Mahama AB, Ayamga EA. They receive antenatal care in health facilities, yet do not deliver there: predictors of health facility delivery by women in rural Ghana. BMC Pregnancy Childbirth. 2018;18(1):125.

29. Esena RK, Sappor M-M. Factors associated with the utilization of skilled delivery services in the Ga east municipality of Ghana part 2: barriers to skilled delivery. Int J Sci Tech Res. 2013;2(8):195-207.
30. Andersen RM, McCutcheon A, Aday LA, Chiu GY, Bell R. Exploring dimensions of access to medical care. Health Serv Res. 1983;18(1):49.

31. Andersen RM. Revisiting the behavioral model and access to medical care: does it matter? J Health Soc Behav. 1995:36(1):1-10.

32. Andersen R, Newman JF. Societal and individual determinants of medical care utilization in the United States. Milbank Mem Fund Q Health Soc. 1973: 51(1):95-124.

33. Gabrysch S, Campbell OM. Still too far to walk: literature review of the determinants of delivery service use. BMC Pregnancy Childbirth. 2009; $9(1): 34$.

34. Tebekaw $Y$, James Mashalla $Y$, Thupayagale-Tshweneagae G. Factors influencing Women's preferences for places to give birth in Addis Ababa, Ethiopia. Obstet Gynecol Int. 2015;2015:1-7.

35. Hosmer DWLS. Applied logistic regression. New York: Wiley; 2000.

36. Bursac Z, Gauss CH, Williams DK, Hosmer DW. Purposeful selection of variables in logistic regression. Source Code Biol Med. 2008;3(1):17.

37. Azimi MD, Najafizada SAM, Khaing IK, Hamajima N. Factors influencing noninstitutional deliveries in Afghanistan: secondary analysis of the Afghanistan mortality survey 2010. Nagoya J Med Sci. 2015;77(1-2):133.

38. Ghana Health Service (GHS): 2011 Annual report. Accra, Ghana. In.; 2012 https://www.ghanahealthservice.org/downloads/ GHS\%202011\%20Annual\%20Report\%20Final\%2014-8-12.pdf. Accessed 15 Dec 2017

39. Alemayehu M, Mekonnen $\mathrm{W}$. The prevalence of skilled birth attendant utilization and its correlates in north West Ethiopia. Biomed Res Int. 2015;2015:1-8.

40. Onah HE, Ikeako LC, lloabachie GC. Factors associated with the use of maternity services in Enugu, southeastern Nigeria. Soc Sci Med. 2006;63(7): 1870-8.

41. Baral Y, Lyons K, Skinner J, Van Teijlingen E. Determinants of skilled birth attendants for delivery in Nepal. Kathmandu Univ Med J. 2012;8(3):325-32.

42. Envuladu E, Agbo H, Lassa S, Kigbu J, Zoakah A. Factors determining the choice of a place of delivery among pregnant women in Russia village of Jos north, Nigeria: achieving the MDGs 4 and 5. Int J Med Biomed Res. 2013;2(1):23-7.

43. Kawakatsu Y, Sugishita T, Oruenjo K, Wakhule S, Kibosia K, Were E, Honda S. Determinants of health facility utilization for childbirth in rural western. Kenya: cross-sectional study. BMC Pregnancy Childbirth. 2014;14(1):265.

44. Borghi J, Ensor T, Neupane BD, Tiwari S. Financial implications of skilled attendance at delivery in Nepal. Tropical Med Int Health. 2006;11(2):228-37.

45. Kowalewski M, Mujinja $\mathrm{P}$, Jahn A. Can mothers afford maternal health care costs? User costs of maternity services in rural Tanzania. Afr J Reprod Health 2002;6(1):65-73.

46. Barnes L. Women's experience of childbirth in rural Jharkhand. Econ Polit Wkly. 2007;42(48):62-70.

47. Mrisho M, Schellenberg JA, Mushi AK, Obrist B, Mshinda H, Tanner M, Schellenberg D. Factors affecting home delivery in rural Tanzania. Tropical Med Int Health. 2007:12(7):862-72.

48. Osubor K, Fatusi AO, Chiwuzie J. Maternal health-seeking behavior and associated factors in a rural Nigerian community. Matern Child Health J. 2006;10(2):159.

49. Hailu D, Berhe $H$. Determinants of institutional childbirth service utilisation among women of childbearing age in urban and rural areas of Tsegedie district, Ethiopia. Midwifery. 2014;30(11):1109-17.

\section{Publisher's Note}

Springer Nature remains neutral with regard to jurisdictional claims in published maps and institutional affiliations. 